\title{
MARKET STRUCTURE AND MARKET DEFINITION: THE CASE OF SMALL MARKET BANKS AND THRIFTS
}

\author{
Andrew Cohen*
}

December 15, 2003

ABSTRACT: This paper introduces a simple method to test between two general approaches to defining bank and thrift product markets. I estimate two models that endogenize market structure using data on banks and thrifts from 1,884 rural markets for the year 2000. The first model assumes that banks and thrifts are in "independent product markets," i.e., that bank profitability depends only on competition from other banks and that thrift profitability depends only on competition from other thrifts. An alternative model is then estimated assuming that banks and thrifts are "perfect strategic substitutes," i.e., that a bank's equilibrium profitability falls equally with the presence of another bank or an additional thrift (and vice-versa). A transformation of the likelihood for the "independent markets" model allows me to test it against the "perfect strategic substitutes" model using Vuong's (1989) non-nested likelihood ratio test. The hypothesis that banks and thrifts compete in independent product markets is soundly rejected against the hypothesis that banks and thrifts are perfect strategic substitutes.

JEL classification: L11, L13, G21, G28

* Federal Reserve Board of Governors. Phone: 202-452-2612, fax: 202-728-5838, email: andrew.m.cohen@frb.gov. The views expressed in this paper are those of the author and do not necessarily reflect the view of the Board of Governors or its staff. I am grateful to Ron Borzekowski, Beth Kiser, Chuck Moul and Robin Prager for useful comments on previous versions. This research has also benefited from comments made by seminar participants at the University of Missouri, the International Industrial Organization Conference and the Federal Reserve Board. Financial Support from the Bankard Fund for Political Economy at the University of Virginia is gratefully acknowledged. Any errors are my own. 


\section{INTRODUCTION}

Market definition is an important issue in the field of industrial organization and particularly for regulators confronted with proposed changes to market structure. Evaluation of a proposed bank merger entails deciding which institutions are valid competitors for the hypothetically merged bank. Defining the relevant product market requires evaluating the set of services that consumers and businesses find substitutable. This exercise can be particularly complicated for retail banks who offer several different services which, for purposes of antitrust, ${ }^{1}$ are grouped together into a single "cluster."

Bank regulators have traditionally computed Herfindahl-Hirschman Indices (HHIs) using deposit market share as a proxy for the degree of competition over the cluster of services offered by banks. Bank mergers receive additional scrutiny if the post-merger HHI increases by more than 200 to a level above 1800 in any market involved in the merger. The issue of whether (or to what extent) to include thrift institutions (i.e., savings banks and savings and loans) as market competitors (e.g., to use their deposits in the HHI calculation) has not been resolved by the relevant antitrust authorities. ${ }^{2}$ Thrifts differ from commercial banks in several respects. Thrifts were precluded from offering demand deposits until the early 1980s and are required to hold most of their assets in real estate. In 1974, the Supreme Court ${ }^{3}$ found that thrifts competed in a different product market than commercial banks because they did not offer the same cluster of services. The relaxation of statutory restrictions that had prevented thrift institutions from offering demand deposit accounts and the ability to engage in limited commercial and industrial lending have greatly reduced many of the practical differences between banks and thrifts.

Recent studies have suggested that thrifts are poor substitutes for banks. Amel and Hannan (2000) estimate residual deposit supply equations for two types of bank accounts and find very small elasticities of the residual bank supply curve. They interpret this as suggesting that only banks should be included in the "market" used in bank merger analysis. Adams, Brevoort and Kiser (2003) find that deposit accounts at banks and thrifts are, at best, very modest substitutes for one another.

\footnotetext{
${ }^{1}$ U.S. v. Philadelphia National Bank, 374 U.S. 321, 83 S.Ct. 1715. 10 L.Ed.2d. 915 (1963).

2 The Office of the Comptroller of the Currency and FDIC give thrifts the same weight as they give other banks in their analyses, but the Federal Reserve Board usually counts $50 \%$ of thrift deposits in its HHI screens. Furthermore, the Department of Justice, which has the power to review bank mergers, includes either $100 \%$ of thrift deposits or none at all (depending on the extent to which the thrift is involved in commercial and industrial lending).

${ }^{3}$ U.S. v. Connecticut National Bank, 418 U.S. 656, 94 S.Ct. 2788, 41 L.Ed.2d. 1016 (1974).
} 
Several recent papers (e.g., Bresnahan and Reiss 1991 and Mazzeo 2002) have exploited the fact that industry market structure provides information about unobserved firm profitability in order to make inferences about the competitiveness of different industries. In particular, the entry decisions of potential competitors and the decision to continue operating an already existing firm depend on several factors including: (1) fixed costs; (2) post-entry competition; and (3) the simultaneous entry/operating decisions of other firms. For a given market structure, it is assumed that each incumbent firm earns positive profits and there is no room for an additional firm to profitably enter the market.

I exploit these models of endogenous market structure in order to further the literature on product market definition in the retail banking industry. I begin by defining two extreme competitive environments for banks and thrifts. In the first, banks and thrifts operate in "independent product markets" implying that bank profitability depends only on the behavior of other banks and similarly for thrifts. In the "perfect strategic substitutes" case, banks are differentiated from other banks to the same extent as they are differentiated from other thrifts. Each hypothesis corresponds to a different game that determines the number of banks and thrifts in the long-run equilibrium. I estimate the parameters of both games and then test between the two specifications.

The perfect strategic substitutes hypothesis corresponds to a game which has a unique equilibrium in the total number of firms, i.e., the sum of banks and thrifts $=\mathrm{N}_{\mathrm{B}}+\mathrm{N}_{\mathrm{T}}$. The mix of banks and thrifts, however, is not uniquely determined. The independent markets hypothesis corresponds to a game (or rather two games, one for banks and one for thrifts) where the number of banks and thrifts are each uniquely determined in equilibrium. After estimating the parameters of the independent markets model, I transform the likelihood so that it represents the probability of observing the total number of firms, i.e., $\mathrm{N}_{\mathrm{B}}+\mathrm{N}_{\mathrm{T}}$. The transformed likelihood is comparable to the likelihood for the perfect strategic substitutes model, allowing me to test between the two using Vuong's (1989) non-nested likelihood ratio test.

This approach to the study of product market definition is novel in several respects. Bank and thrift profits are specified as reduced form functions of the number of banks and the number of thrifts, as well as demand and cost shifters particular to the local market. The principle advantage of this specification is that it allows for analysis of competition between banks and thrifts in terms of the cluster of services, rather than for individual products. Another advantage is that it does not rely on 
price and quantity data which are rarely available at disaggregate (bank/product/market specific) levels. Finally, this approach is quite parsimonious and easy to implement. This comes at the cost of providing less information than would a more fully specified model capable of accommodating cases intermediate to the two regimes I consider in this paper.

\section{A MODEL OF ENDOGENOUS LONG-RUN MARKET STRUCTURE}

I assume that, in addition to existing banks and thrifts, there are a number of potential bank thrift entrants. It is assumed that all existing firms earn positive profits, and that any potential firms would earn negative profits if they chose to enter the market. I assume that long-run profits for all firms of a given type operating in a particular market can be expressed as a reduced form function of the number of active firms in the market, demand and cost shifters, $\mathbf{X}$, and an unobservable component.

Let $\Pi_{\mathbf{B}}\left(\mathbf{N}_{\mathbf{B}}, \mathbf{N}_{\mathbf{T}} ; \mathbf{X}\right)$ represent the expected long-run profits for a bank that chooses to operate in a given market, where $\mathrm{N}_{\mathrm{B}}$ and $\mathrm{N}_{\mathrm{T}}$ are the number of banks and thrifts in the market, respectively. Define $\Pi_{\mathbf{T}}\left(\mathbf{N}_{\mathbf{B}}, \mathbf{N}_{\mathbf{T}} ; \mathbf{X}\right)$ similarly. ${ }^{4}$ The return associated with not operating a bank or thrift is normalized to zero.

All long-run equilibrium market structures are characterized by the number of banks and thrifts that operate in the market. ${ }^{5}$ The following two conditions must hold in any Nash Equilibrium: (1) all firms, of either type, that choose to operate must expect to earn positive profits; and (2) an additional entrant, of either type, would not be profitable. These conditions can be expressed as:

$$
\begin{array}{lll}
\Pi_{\mathrm{B}}\left(\mathrm{N}_{\mathrm{B}}, \mathbf{N}_{\mathrm{T}}\right) \geq \mathbf{0} & \Pi_{\mathrm{B}}\left(\mathrm{N}_{\mathrm{B}}+\mathbf{1}, \mathbf{N}_{\mathrm{T}}\right)<0 \\
\Pi_{\mathrm{T}}\left(\mathbf{N}_{\mathrm{T}}, \mathbf{N}_{\mathrm{B}}\right) \geq \mathbf{0} & \Pi_{\mathrm{T}}\left(\mathbf{N}_{\mathrm{T}}+\mathbf{1}, \mathbf{N}_{\mathrm{B}}\right)<\mathbf{0}
\end{array}
$$

The two hypotheses that I test between can be distinguished in terms of restrictions on the relationship of the partial derivatives of the profit. In particular, the independent markets model restricts the "crosstype" effects to be zero. That is,

$$
\Delta \Pi_{\mathbf{B}}\left(\mathbf{N}_{\mathbf{B}}, \mathbf{N}_{\mathrm{T}}\right) / \Delta \mathbf{N}_{\mathrm{T}}=\Delta \Pi_{\mathrm{T}}\left(\mathbf{N}_{\mathbf{B}}, \mathbf{N}_{\mathrm{T}}\right) / \Delta \mathbf{N}_{\mathbf{B}}=\mathbf{0}
$$

\footnotetext{
${ }^{4}$ The reduced-form profit function is restrictive in the sense that all thrifts in a particular market are equally profitable, and all banks in a particular market are equally profitable (though returns may differ between banks and thrifts). This assumption, however, is not as restrictive as it may seem since, if one chooses to think of the profit measure as a rate of return, one need only assume that that profit levels are proportional to firm size.

${ }^{5}$ Given the assumptions I have made, the model does not predict the identity of the extant firms.
} 
implying that thrifts have no effect on bank profits and vice-versa. The independent markets model, therefore, can be written as:

$$
\Pi_{B}\left(\mathbf{N}_{B}, \mathbf{N}_{T}\right)=\Pi_{B}\left(N_{B}\right) \text { and, } \Pi_{T}\left(N_{B}, N_{T}\right)=\Pi_{T}\left(N_{T}\right)
$$

The perfect strategic substitutes model restricts the cross-type effects to be identical to the same-type effects. That is,

$$
\begin{aligned}
& \Delta \Pi_{\mathrm{B}}\left(\mathbf{N}_{\mathrm{B}}, \mathbf{N}_{\mathrm{T}}\right) / \Delta \mathbf{N}_{\mathrm{T}}=\Delta \Pi_{\mathrm{B}}\left(\mathbf{N}_{\mathrm{B}}, \mathbf{N}_{\mathrm{T}}\right) / \Delta \mathbf{N}_{\mathrm{B}}= \\
& \Delta \Pi_{\mathrm{T}}\left(\mathbf{N}_{\mathbf{B}}, \mathbf{N}_{\mathrm{T}}\right) / \Delta \mathbf{N}_{\mathrm{T}}=\Delta \Pi_{\mathrm{T}}\left(\mathbf{N}_{\mathrm{B}}, \mathbf{N}_{\mathrm{T}}\right) / \Delta \mathbf{N}_{\mathbf{B}}
\end{aligned}
$$

implying that an additional bank has the same effect on bank profitability as an additional thrift does (and vice-versa). In this case, the profit function of a thrift is not separately identified from that of a bank. Therefore, the perfect strategic substitutes model can be written as:

$$
\Pi_{B}\left(\mathbf{N}_{B}, \mathbf{N}_{T}\right)=\Pi_{T}\left(\mathbf{N}_{B}, \mathbf{N}_{T}\right)=\Pi\left(\mathbf{N}_{B}+\mathbf{N}_{T}\right)
$$

Equilibrium market configurations under each hypothesis are therefore characterized as follows. For the independent markets hypothesis:

$$
\Pi_{\mathbf{B}}\left(\mathbf{N}_{\mathbf{B}}\right) \geq \mathbf{0}>\Pi_{\mathbf{B}}\left(\mathbf{N}_{\mathbf{B}}+\mathbf{1}\right) \quad \text { and }, \quad \Pi_{\mathbf{T}}\left(\mathbf{N}_{\mathbf{T}}\right) \geq \mathbf{0}>\Pi_{\mathbf{T}}\left(\mathbf{N}_{\mathbf{T}}+\mathbf{1}\right)
$$

and, for the perfect strategic substitutes hypothesis,

$$
\Pi\left(\mathbf{N}_{\mathbf{B}}+\mathbf{N}_{\mathrm{T}}\right) \geq \mathbf{0}>\Pi\left(\mathbf{N}_{\mathrm{B}}+\mathbf{N}_{\mathrm{T}}+\mathbf{1}\right)
$$

The likelihood under each hypothesis is given by the probability that the inequalities in (5) and (6), respectively, hold.

The generic profit function associated with a given type, $A$, operating in market $m, \Pi_{\mathbf{A}}\left(\mathbf{N}_{\mathbf{m}} ; \mathbf{X}_{\mathbf{m}}\right)$, is parameterized as follows:

$$
\Pi_{A}\left(N_{m} ; X_{m}\right)=\sum_{i=1}^{N_{m}-1} \alpha_{A i}+f_{A}\left(X_{m}\right)+\varepsilon_{A m}
$$

where the $\alpha$ 's capture the incremental effects of additional competitiors, $f_{A}$ is a function of the demand and cost shifters which I approximate as a second order polynomial, and $\varepsilon_{\mathrm{Am}}$ is a market/type specific unobservable which I assume to be distributed iid standard normal. Parameter estimates are obtained by maximizing the likelihood obtained by substituting (7) into (5) ${ }^{6}$ or (6). Given the normality

\footnotetext{
${ }^{6}$ The covariance between $\varepsilon_{\mathrm{Bm}}$ and $\varepsilon_{\mathrm{Tm}}$ is not identified. Therefore, the bank and thrift likelihoods are independent.
} 
assumption, the likelihood is an ordered probit in the number of firms of the appropriate type (this will vary according to the hypothesis).

\section{RESULTS}

I estimate the parameters of the profit functions corresponding to the two hypotheses using data from 1,884 non-MSA ${ }^{7}$ labor market areas (LMAs) in the continental U.S. with populations less than 100,000 as of June $30,2000 .^{8}$ Table 1 presents the observed market configurations. ${ }^{9}$ The reduced form profit function depends on a vector of market characteristics, $\mathbf{X}$, that is intended to capture demand and cost shifters. Summary statistics for these variables are presented in Table 2.

I test the two models against one another using Vuong's non-nested likelihood ratio test. ${ }^{10}$ The likelihood for the independent markets hypothesis is defined as $\mathrm{L}^{\mathrm{INDEP}}\left(\mathrm{N}_{\mathrm{B}}, \mathrm{N}_{\mathrm{T}}\right)=\mathrm{L}_{\mathrm{B}}\left(\mathrm{N}_{\mathrm{B}}\right)^{*} \mathrm{~L}_{\mathrm{T}}\left(\mathrm{N}_{\mathrm{T}}\right)$ while the likelihood for the perfect strategic substitutes hypothesis is defined as $\mathrm{L}^{\mathrm{SUB}}\left(\mathrm{N}_{\mathrm{B}}+\mathrm{N}_{\mathrm{T}}\right)$. Under the perfect strategic substitutes hypothesis, the likelihood of observing $\mathrm{N}_{\mathrm{B}}$ banks and $\mathrm{N}_{\mathrm{T}}$ thrifts is not defined since equilibrium market structure is unique in the total number of firms, but not in the number of firms of each type. Therefore, I will need to compare predictions about the total number of firms under the two competing hypotheses. That is, I will need to construct the likelihood of observing $\left(\mathrm{N}_{\mathrm{B}}+\mathrm{N}_{\mathrm{T}}\right)$ firms under the independent product markets. I construct the likelihood, $\ell^{\mathrm{INDEP}}\left(\mathrm{N}_{\mathrm{B}}+\mathrm{N}_{\mathrm{T}}\right)$, by summing the likelihoods of all pairs $\left(\mathrm{N}_{B}, \mathrm{~N}_{T}\right)$ that equal $\mathrm{N}_{\mathrm{B}}+\mathrm{N}_{\mathrm{T}}$, for each market. Let $\mathrm{A}(\mathrm{N})$ denote the set of possible (non-negative) integer combinations of banks and thrifts that sum to $\mathrm{N}$. Then the likelihood contribution for market $\mathrm{m}$, of observing $\mathrm{N}_{\mathrm{Bm}}+\mathrm{N}_{\mathrm{Tm}}$ total firms under the independent markets hypothesis is given by:

$$
\ell_{\mathrm{m}}^{\text {INDEP }}\left(\mathrm{N}_{\mathrm{Bm}}+\mathrm{N}_{\mathrm{Tm}}\right)=\sum_{\left(N_{B}, N_{T}\right) \in A\left(N_{B m}+N_{T m}\right)} \mathrm{L}_{\mathrm{m}}^{\text {INDEP }}\left(N_{B}, N_{T}\right)
$$

\footnotetext{
${ }^{7}$ I focus on smaller geographic markets because they are unlikely to contain distinct submarkets. In addition, most mergers that are challenged by regulators on competitive grounds are done so because of their effect on smaller non-MSA markets. Therefore, the role of thrifts as potential competitors for banks is of greater interest in the non-MSA markets.

${ }^{8}$ The Bureau of Labor Statistics defines LMAs as integrated economic areas, based on commuting patterns between counties. Contiguous counties are combined into a single LMA if at least 15 percent of the workers from one county commute for work to the other. While counties have typically been used to delineate geographic markets in studies of bank competition, I prefer using LMAs since political boundaries may not represent meaningful economic distinctions. Using LMAs provides some reassurance that two neighboring markets are indeed competitively distinct.

${ }^{9}$ More than half of the markets have no thrift presence. This fact alone does not favor either hypothesis. Intuitively, if the lack of thrifts can be predicted by market characteristics, I should find support for the independent markets hypothesis. On the other hand, if the lack of thrifts can be predicted by the number of banks conditional on market characteristics, I should find support for the perfect strategic substitutes hypothesis.

${ }^{10}$ Detailed results from the ordered probits corresponding to the two hypotheses are available by request from the author.
} 
Having defined the likelihood of observing the total number of firms under each of the two hypotheses, it is now possible to test between them. I use the non-nested likelihood test described in Vuong (1989) to select between the independent product markets hypothesis ("INDEP") and the perfect strategic substitutes hypothesis ("SUB"). The hypotheses to be tested are:

$\begin{array}{ll}\mathrm{H}_{0}: & \text { INDEP and SUB are indistinguishable from one another } \\ \mathrm{H}_{\text {INDEP }} & \text { INDEP is superior to SUB } \\ \mathrm{H}_{\mathrm{SUB}}: & \text { SUB is superior to INDEP }\end{array}$

The test statistic

$$
\psi=\frac{\log \left(\frac{\ell_{\text {INDEP }}}{L_{\text {SUB }}}\right)}{\sqrt{n}\left[\operatorname{se}\left(\log \left(\frac{\ell_{\text {INDEP }}}{L_{S U B}}\right)\right)\right]}
$$

converges in distribution to a standard normal under the null hypothesis and has the following interpretation:

$$
\begin{aligned}
& \text { Under } \mathrm{H}_{0}: \quad \quad \psi=0 \\
& \text { Under } \mathrm{H}_{\text {INDEP }}: \quad \psi>0 \\
& \text { Under } \mathrm{H}_{\text {SUB }}: \quad \psi<0
\end{aligned}
$$

The likelihood under the independent markets hypothesis is $\mathbf{- 3 0 9 0 . 2 5}$. The likelihood under the perfect strategic substitutes hypothesis is $\mathbf{- 3 0 7 1 . 1 9}$. The test statistic $\psi$ is equal to $\mathbf{- 2 . 6 9}{ }^{11}$ providing evidence against $\mathrm{H}_{0}$ and $\mathrm{H}_{\text {INDEP }}$ in favor of $\mathrm{H}_{\text {SUB }}$ with a significance level of .004 .

\section{CONCLUSION}

In this paper I examine two competing hypotheses regarding the interaction between retail banks and thrifts. I estimate a model of endogenous market structure corresponding to each hypothesis. By transforming the likelihood from the independent markets model, I am able to test between the two

\footnotetext{
${ }^{11}$ The reported test statistic is unadjusted. Vuong suggests adjustments to the test statistic to account for differences in the number of parameters estimated in each model. The Aikake adjusted value of the statistic is -2.93 which would provide even stronger evidence in favor of the perfect strategic substitutes model.
} 
models. The results provide very strong evidence supporting the perfect strategic substitutes hypothesis. $^{12}$

\section{REFERENCES}

Adams, R., Brevoort K. and Kiser E., "Who Competes with Whom? The Case of Depository Institutions," Federal Reserve Board, working paper.

Amel, Dean, and Timothy Hannan, "Defining Banking Markets According to the Principles Recommended in the Merger Guidelines," The Antitrust Bulletin 45 (Fall 2000) pp. 615-639.

Bresnahan T. and Reiss P. "Entry in Concentrated Markets," Journal of Political Economy, 99 (October 1991) pp. 977-1009.

Mazzeo, M. "Product Choice and Oligopoly Market Structure," RAND Journal of Economics, 33 (Summer 2002) pp. 1-22.

Vuong, Q. "Likelihood Ratio Tests for Model Selection and Non-Nested Hypotheses," Econometrica 57 (March 1989) pp. 307-333.

\footnotetext{
${ }^{12}$ An important caveat to these results is that they do not consider the role of credit unions. In principle, it would be possible to incorporate credit unions (or other types of firms) into this type of analysis though comprehensive data on credit union presence for this period is difficult to find.
} 
Table 1: Observed Market Structures

\begin{tabular}{|c|c|c|c|c|c|c|c|c|c|c|c|c|c|c|}
\hline & \multicolumn{13}{|c|}{ Banks } \\
\hline & & 0 & 1 & 2 & 3 & 4 & 5 & 6 & 7 & 8 & 9 & 10 & $11+$ & Total \\
\hline \multirow{5}{*}{ Thrifts } & 0 & 13 & 111 & 195 & 222 & 168 & 119 & 100 & 48 & 30 & 16 & 8 & 19 & 1,049 \\
\hline & 1 & 4 & 14 & 60 & 75 & 90 & 94 & 67 & 60 & 40 & 32 & 17 & 27 & 580 \\
\hline & 2 & 0 & 6 & 12 & 16 & 23 & 28 & 30 & 20 & 18 & 14 & 9 & 9 & 185 \\
\hline & $3+$ & 0 & 0 & 1 & 3 & 13 & 7 & 4 & 7 & 11 & 8 & 3 & 13 & 70 \\
\hline & Tota & 17 & 131 & 268 & 316 & 294 & 248 & 201 & 135 & 99 & 70 & 37 & 68 & 1,884 \\
\hline
\end{tabular}

Table 2: Summary Statistics for $\mathrm{X}$ variables

Mean Variance Minimum Maximum

$\begin{array}{lcccc}\text { Population } & 23,299 & 19,944 & 65 & 99,428 \\ \text { Population Growth } & 0.007 & 0.013 & -0.048 & 0.072 \\ \text { Per Capita Income } & 20,943 & 3,980 & 5,475 & 69,960 \\ \text { Per Capita Income Growth Rate } & 0.038 & 0.011 & -0.056 & 0.100 \\ \text { Number of establishments } & 542 & 508 & 1 & 4,855 \\ \text { Number of farms } & 617 & 452 & 0 & 4,302 \\ \text { Number of jobs } & 9,075 & 9,056 & 50 & 65,685 \\ \text { Persons per square mile } & 34.467 & 33.995 & 0.097 & 312.735 \\ \text { Occupancy Rate } & 0.834 & 0.097 & 0.230 & 0.967 \\ \text { Ownership Rate } & 0.754 & 0.058 & 0.343 & 0.896\end{array}$

Sources: Agricultural Census, Bureau of Economic Analysis, and Census Bureau 